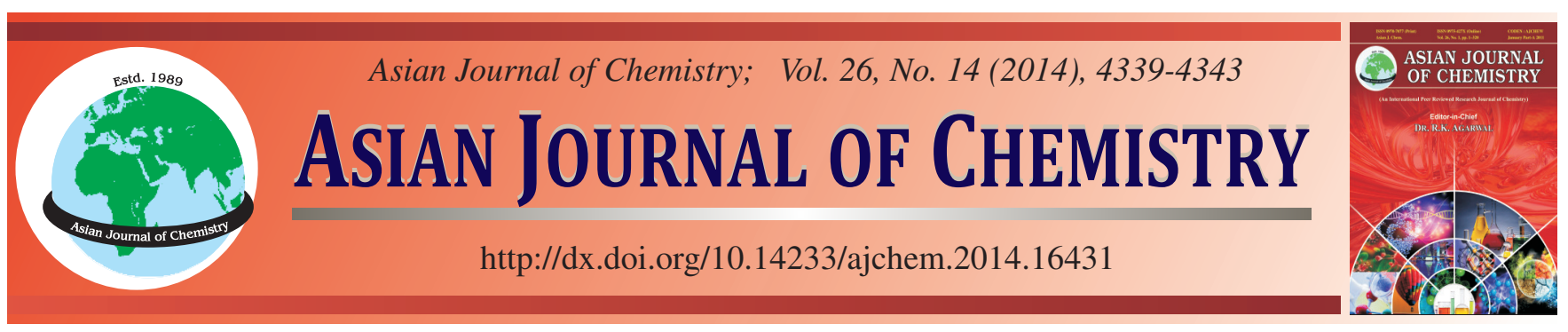

\title{
Evaluation of Two Bryophytes (Funaria hygrometrica and Polytrichum commune) as a Source of Natural Antioxidant
}

\author{
Uzma Hanif ${ }^{1}$, Hafiz Ahsan Ali ${ }^{1}$, Durre Shahwar ${ }^{2}$, Sidra Farid ${ }^{2}$ and Saiqa Ishtiaq,
}

\begin{abstract}
${ }^{1}$ Department of Botany, Government College University, Lahore-54000, Pakistan
${ }^{2}$ Department of Chemistry, Government College University, Lahore-54000, Pakistan

${ }^{3}$ University College of Pharmacy, University of the Punjab, Lahore-54000, Pakistan
\end{abstract}

*Corresponding author: E-mail: saiqa_ishtiaq@yahoo.com

\begin{abstract}
Extraction of two Bryophyte plants i.e. Funaria hygrometrica and Polytrichum commune was done through methanol in order of their increasing polarity using Soxhlet apparatus. Total phenolic contents were determined with Folin-Ciocalteu reagent which ranged from 30.5 to $547 \mathrm{mg} \mathrm{GAE} / \mathrm{g}$ of extract. Polytrichum showed significant but slightly less phenolics contents while that of Funaria showed the high phenolic contents having a value of 1630 for Funaria and 975 for that of Polytrichum. Antioxidant activities of these extracts were evaluated through DPPH radical scavenging, Ferric thiocyanate method, ABTS ${ }^{\bullet+}$ Assay, FRAP Assay, Superoxide Anion Radical Scavenging Activity, Total phenolics and total flavonoids determination assay, Metal chelating activity, metal chelating effect and ferric thiocyanate (FTC) methods. In terms of TEAC values the extracts of Funaria and Polytrichum had the TEAC value as 97.5 and 71.06 . The results of DPPH assay showed that Funaria and Polytrichum showed least $\mathrm{IC}_{50}$ values, hence they have a greater potential. The methanolic extract of Polytrichum showed a very high concentration of flavonoids, 3636.36 of Polytrichum while the other plant sample (Funaria) contained significant but slightly less quantities of flavonoids as 1751.8 .
\end{abstract}

Keywords: DPPH, ABTS, FRAP, FTC, Radical-scavenging, Total phenolics and Total flavonoids.

\section{INTRODUCTION}

Recently there has been an upsurge of interest in the therapeutic potential of medicinal plants as antioxidants in reducing free radical-induced tissue injury ${ }^{1}$. The major constituents of biological membranes are lipids and proteins. Reactive oxygen species can easily initiate damage of the cell membrane constituent that is, phospholipids and lipoproteins by propagating a reaction cycle $\mathrm{e}^{2,3}$. It has been mentioned by many authors that antioxidant activity of plants is due to their phenolic compounds ${ }^{4-7}$. Bryophytes are considered amongst the oldest land plants. Lack of economic importance, insignificant number and size and inconspicuous distribution have made bryophytes apparently of no use when compared to their tracheophyte cousins. Bryophytes have been investigated extensively for active constituents and pharmacological activity. Bryophytes possess strong antioxidative enzymatic machinery which helps them to cope up with extreme climates and stresses ${ }^{8,9}$. In longer term, plant species identified as having high levels of antioxidant activity in vitro may be of value in the design of further studies to unravel novel treatment strategies for disorders associated with free radicalsinducedtissue damage. A number of synthetic antioxidants, butylated hydroxyanisole (BHA), butylated hydroxytoluene (BHT) and tertiary butyl hydroquinone (TBHQ) have been added to foodstuffs but, are reported to cause liver disorders ${ }^{10}$. Therefore, attention has been directed towards the purification of natural antioxidants from botanical sources, especially edible plants. The study was conducted to evaluate the antioxidant activity of these two bryophyte plant species by applying different antioxidant assays like FTC, FRAP, DPPH radical scavenging, etc.

\section{EXPERIMENTAL}

Folin-Ciocalteu (FC) reagent, DPPH, BHT, $\alpha$-tocopherol, gallic acid, linoleic acid and potassium thiocyanate were purchased from Fluka and Sigma-Aldrich (USA). All other chemicals and solvents were analytical grade.

Preparation of plant extracts: Whole plant samples were collected from Donga Galli Murree, Pakistan during their growing season. The plant material was authenticated at Botany Department GCU Lahore. After collection, plants were kept in laboratory (shade) at room temperature for drying. These plants were then ground in pestle and mortar to fine powdered form then extracted in methanol using Soxhlet apparatus. Crude extracts were filtered and concentrated at reduced temperature using rotary evaporator. 
Determination of total phenolic content: Total phenolic contents of the extracts were determined by Folin-Ciocalteu reagent ${ }^{11}$. $0.1 \mathrm{~mL}$ of extract was combined with $2.8 \mathrm{~mL}$ of 10 $\% \mathrm{Na}_{2} \mathrm{CO}_{3}$ and $0.1 \mathrm{~mL}$ of $2 \mathrm{~N}$ Folin-Ciocalteu reagents. After $40 \mathrm{~min}$, absorbance was measured at $725 \mathrm{~nm}$ using UV-visible spectrophotometer (CECIL-7200). The results were determined as mg equivalent of gallic acid per gm of extractby computing with standard calibration curve $\left(R^{2}=0.9909\right.$ value $)$ constructed for different concentrations of gallic acid.

FTC assay: The antioxidant activity of extracts on inhibition of linoleic acid per oxidation was assayed by ferric FTC ${ }^{12}$. $0.1 \mathrm{~mL}$ of the ethanolic solution of the extract $(5 \mathrm{mg} / \mathrm{mL})$ was mixed with $10 \mathrm{~mL}$ of absolute ethanol, $10 \mathrm{~mL}$ of $0.2 \mathrm{M}$ phosphate buffer (pH 6.0) and $2 \mathrm{~mL}$ of $2 \%$ (v/v) linoleic acid. All the samples were incubated at $40{ }^{\circ} \mathrm{C}$. At regular intervals, (48 h) $5 \mathrm{~mL}$ ethanol, $0.1 \mathrm{~mL} 0.02 \mathrm{M}$ ferrous chloride in $3.5 \%$ $\mathrm{HCl}$ and $0.1 \mathrm{~mL}$ of aq. $20 \%$ ammonium thiocyanate was added in the above solution and absorbance was recorded at $500 \mathrm{~nm}$. Gallic acid, BHT and $\alpha$-tocopherol were used as standard reference in $2 \mathrm{mg} / \mathrm{mL}$ concentration.

DPPH radical scavenging assay: The antioxidant activity of extracts was measured in termsof radical scavenging ability by DPPH method $^{13}$. Methanolic solution $(1 \mathrm{~mL})$ of different extracts at $100 \mu \mathrm{g} / \mathrm{mL}$ concentration was added to $1 \mathrm{~mL}$ methanolic solution of DPPH $(2 \mathrm{mg} / \mathrm{mL})$. The absorbance was measured at $517 \mathrm{~nm}$ after $0.5 \mathrm{~h}$. The results were evaluated as percentage scavenging of radical $\left(\%\right.$ scavenging of $\mathrm{DPPH}^{\circ}=$ Abs. of blank - Abs. of sample/Abs. of blank $\times 100)$. $\mathrm{IC}_{50}$ value (concentration of sample where absorbanceof DPPH decreases $50 \%$ with respect to absorbance ofblank) of extracts were determined. The results were compared with standards (gallic acid and BHT).

ABTS $^{\bullet+}$ assay protocol: ABTS $^{\bullet+}$ Assay was initially developed by Miller \& Rice in 1993 and later improved by ${ }^{14}$. For the evaluation of antioxidant activity $\mathrm{ABTS}^{\bullet+}$ assay was done as described by Re et al. ${ }^{14} .7 \mathrm{mM}$ solution of ABTS was prepared in double distilled water, which generated ABTS $^{\circ+}$ while reacting with $2.45 \mathrm{mM}$ potassium persulfate after $24 \mathrm{~h}$ on standing under dark. The $\mathrm{ABTS}^{\bullet+}$ stock solution was diluted with PBS buffer of pH 7.4 or methanol to an absorbance of $0.70+0.02$ at $734 \mathrm{~nm}$. For the evaluation of antioxidant activity, added $10 \mu \mathrm{l}$ of sample to $2.99 \mathrm{~mL}$ of diluted solution of $\operatorname{ABTS}^{\circ+}(\mathrm{A}=0.70+0.02)$ and noted the change in absorbance after every $1 \mathrm{~min}$ interval for $8 \mathrm{~min}$. Appropriate solvent blank was run in parallel. All the samples were run in triplicate and mean values of absorbance were calculated. A dose response curve of Trolox was prepared by plotting its absorbance at 734 $\mathrm{nm}$ and $\%$ age inhibition for each sample was calculated by using this formula

\section{$\%$ age inhibition $($ at $734 \mathrm{~nm})=\left(1-\mathrm{A}^{\mathrm{f}} / \mathrm{A}^{0}\right) \times 100$}

Ferric reducing antioxidant power: The ferric reducing ability of plant sample was determined by the method proposed by ${ }^{15}$. The FRAP reagent was prepared by mixing $25 \mathrm{~mL}$ of 300 $\mathrm{mM}$ acetate buffer of $\mathrm{pH} 3.6,2.5 \mathrm{~mL}$ of $10 \mathrm{mM}$ TPTZ solution in $40 \mathrm{mM} \mathrm{HCl}$ and $20 \mathrm{mM}$ ferric chloride $(2.5 \mathrm{~mL})$. The absorbance was measured at $593 \mathrm{~nm}$ after the mixing of $3 \mathrm{~mL}$ FRAP reagent, $300 \mu \mathrm{l}$ of distilled water and $100 \mu \mathrm{l}$ of sample. FRAP value was calculated from the standard curve of iron (II) sulphate.
Determination of total flavonoid: The TFC content of plant fractions was determined by following method developed by ${ }^{16} .0 .25 \mathrm{~mL}$ of plant sample/quercetin standard solution was mixed with $1250 \mu \mathrm{l}$ of distilled water in a test tube then added $75 \mu \mathrm{l}$ of $\mathrm{NaNO}_{2}$ solution. After $5 \mathrm{~min}$ stay added $0.5 \mathrm{~mL}$ of 1 $\mathrm{M} \mathrm{NaOH}$ and raised the volume with distilled water to a final volume of $2.5 \mathrm{~mL}$. The absorbance of this sample solution was measured at $510 \mathrm{~nm}$. TFC contents were determined from the standard curve of quercetin and expressed as $\mathrm{mg}$ of quercetin equivalents per gram of sample.

Metal chelating activity: The ability of plant extracts to chelate Iron (II) was determined by the known method ${ }^{17}$. The reaction mixture was prepared by mixing $100 \mu \mathrm{L}$ of sample with $0.05 \mathrm{~mL}$ of $\mathrm{FeSO}_{4}$ and $0.2 \mathrm{~mL}$ of $5 \mathrm{mM}$ ferrozine and raised its volume to $4 \mathrm{~mL}$ with double distilled ethanol. This reaction mixture was allowed to stand for $10 \mathrm{~min}$ at room temperature. Then the absorbance of the solution at $562 \mathrm{~nm}$ was noted. The results were expressed as the \%age of bound iron, which can be calculated from theformula shown below or in terms of EDTA standard:

$\%$ age bound iron $=[($ A control-A sample $) / A$ control $]$

Superoxide anion radical scavenging activity: This activity of plant extracts was evaluated by the known method ${ }^{18}$. In this method, NADH-PMS system was employed for the in vitro generation of superoxide radical anions. The reaction mixture was prepared by mixing $100 \mu \mathrm{l}$ of sample, $624 \mu \mathrm{M}$ of NADH, $200 \mu \mathrm{M}$ NBT and $80 \mu \mathrm{M}$ PMS in phosphate buffer $(0.1 \mathrm{M})$ of $\mathrm{pH} 7.4$. Then absorbance of reaction mixture was measured at $560 \mathrm{~nm}$. The \% age scavenging of each sample was calculated from the formula:

$$
\% \text { age scavenging }=[1-\mathrm{AS} / \mathrm{AB} \times 100]
$$

\section{RESULTS AND DISCUSSION}

Total phenolic contents: Phenolic compounds are commonly present in both edible and non-edible plants and exhibit multiple biological effects including antioxidant activity ${ }^{19}$. The phenolic contents of the selected plant extracts were determined by FC reagent and expressed as gallic acid equivalents in $\mathrm{mg} / \mathrm{g}$ of crude extract. It is thought that phenolic compounds can attribute to the total antioxidant activity. The methanol extract of Funaria hygrometrica showed the highest phenolic contents (1630), while other plant sample (Polytrichum commune) contained relatively less phenolic contents (975). Total phenolic contents of solvent extracts are shown in Fig.1.

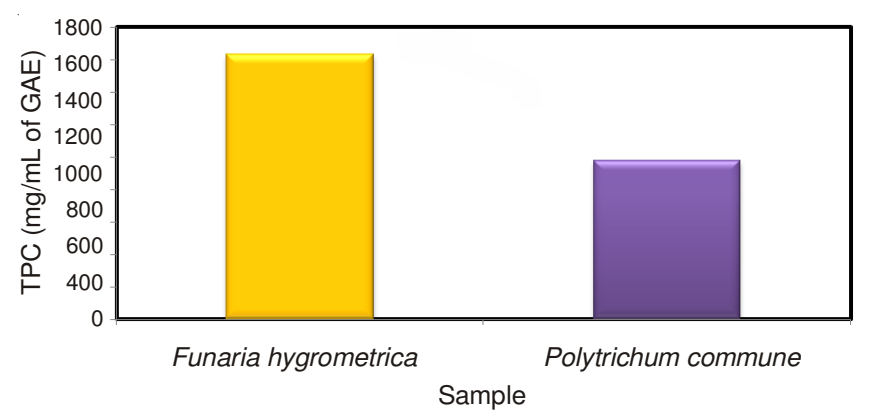

Fig. 1. Total phenol contents 


\section{Antioxidant activities}

DPPH radical scavenging assay: Antioxidants react with $\mathrm{DPPH}^{\circ}$, which is a stable freeradical and convert it to $1,1^{\prime}$ diphenyl-2-picryl hydrazine ${ }^{20}$. The degree of decolourization of the purple coloured solution of $\mathrm{DPPH}^{\bullet}$ indicated the scavenging potential of the antioxidant compound. It was found that the radical scavenging activity of Funaria was more than that of BHT (78.9\%) and $\alpha$-tocopherol (77.4\%), whereas for Polytrichum the $(94.7 \%)$ and $\alpha$-tocopherol (80.6\%) (Figs. 2-3).

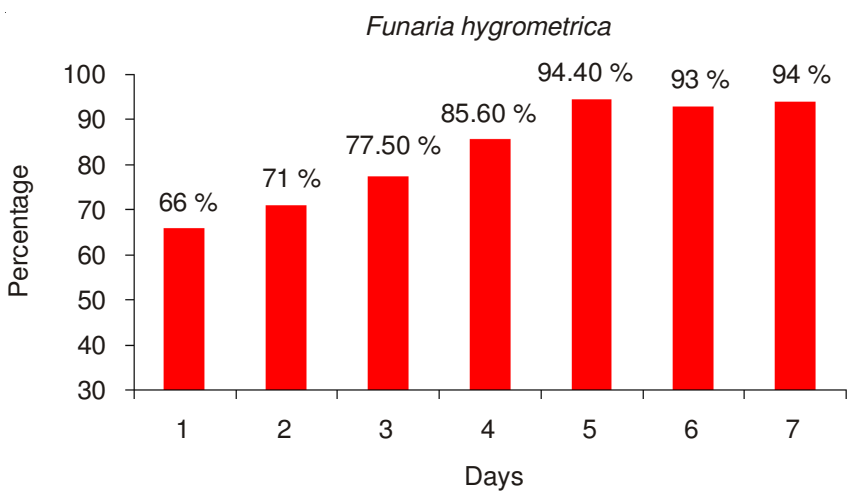

Fig. 2

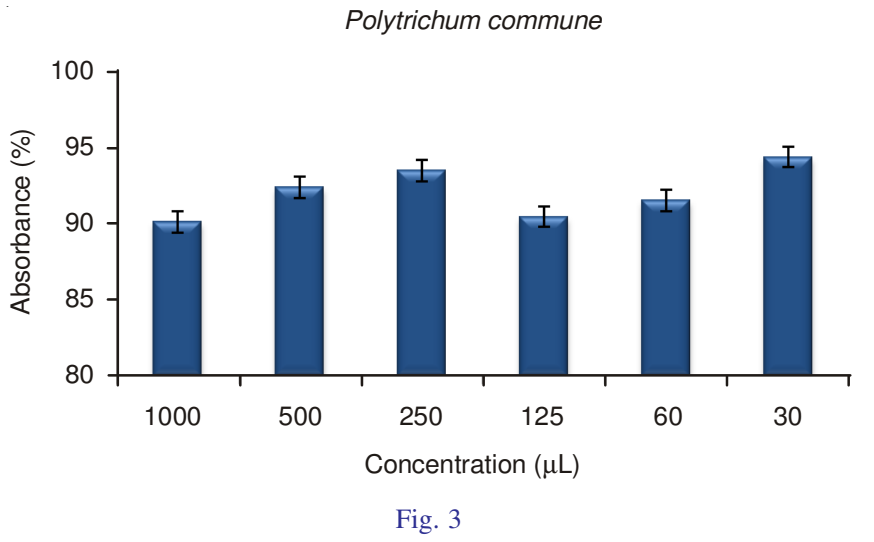

Ferric thiocyanate assay: The methanolic extract of Polytrichum showed a maximum value of $95 \%$ during the seven days experimentation while the lowest value was $82.1 \%$ and Funaria showed a maximum value of $94.4 \%$ and a lowest value of $66 \%$ during the seven days. This is in agreement with the previous reported work ${ }^{21-24}$. The results were comparable with BHT and $\alpha$-tocopherol (Figs. 4 and 5)

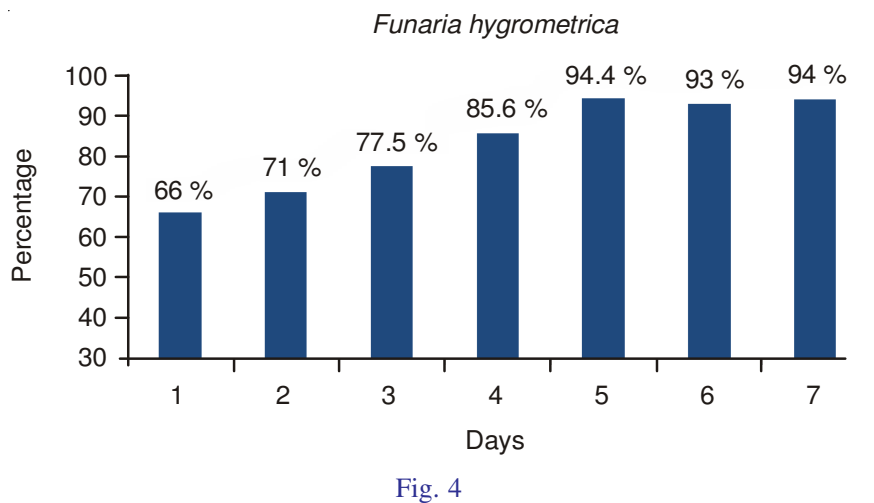

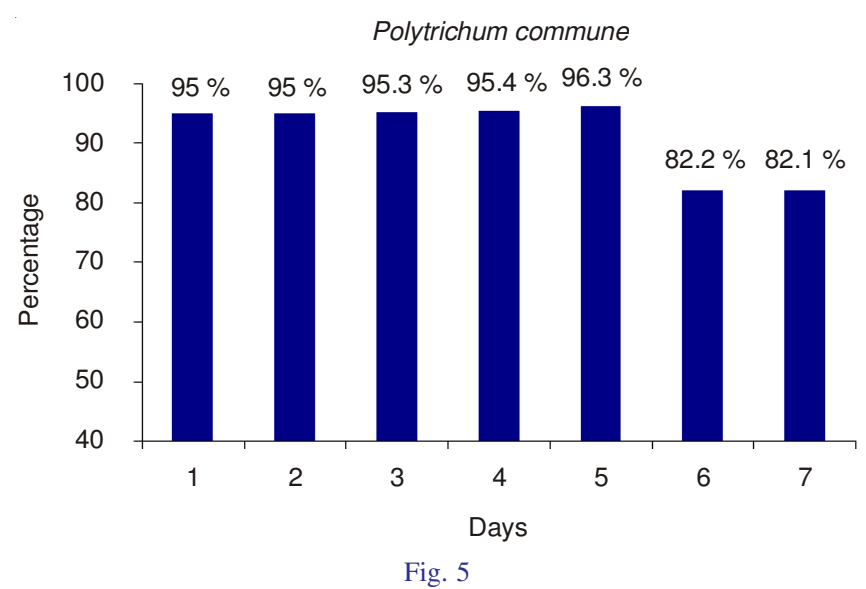

ABTS $^{\circ+}$ assay: 2,2'-Azinobis(3-ethylbenzo thiazoline)6-sulphonic acid (ABTS) is a phenothiazine drug, when reacting with potassium persulfate, forms a green coloured radical cation. The results of ABTS assay were expressed in terms of TEAC value. As TEAC is the measure of effective antioxidant activity of the substance and stands for "Trolox equivalent antioxidant capacity". A higher TEAC value referred to a greater antioxidant potential of sample. As all the samples had a great antioxidant potential, but the extract of Polytrichum commune showed relatively lower potential of antioxidant activity having the TEAC value of $71.06 \mathrm{mM}$ of Trolox equivalence. While the extracts of Funaria hygrometrica had greatly higher antioxidant potential in terms of TEAC values that is 97.5 (Fig. 6).

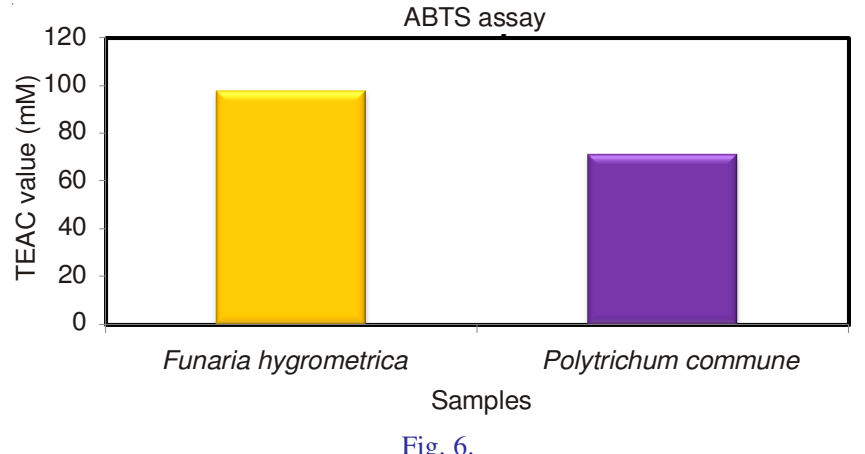

Total flavonoid contents: The principle of this colorimetric method is that aluminum chloride forms acid stable complexes with the C-4 keto group and either the C-3 or C-5 hydroxyl group of flavones and flavonols. In addition, aluminum chloride forms acid labile complexes with the orthodihydroxyl groups in the A- or B-ring of flavonoids which absorbs maximally at $400 \mathrm{~nm}$. The total flavonoid contents of plant are expressed in terms of quercetin equivalents. The methanol extract of Polytrichum commune showed a high concentration of flavonoids (3636.36) while the other plant sample (Funaria hygrometrica) contained significant but slightly less quantities of flavonoids (1751.8) (Fig. 7).

Superoxide radical scavenging activity: This assay employed an in vitro generation model [PMS/NADH/O ${ }_{2}$ of superoxide radical anions and nitro blue tetrazolium (NBT) as a probe. The results of this assay are expressed in terms of 


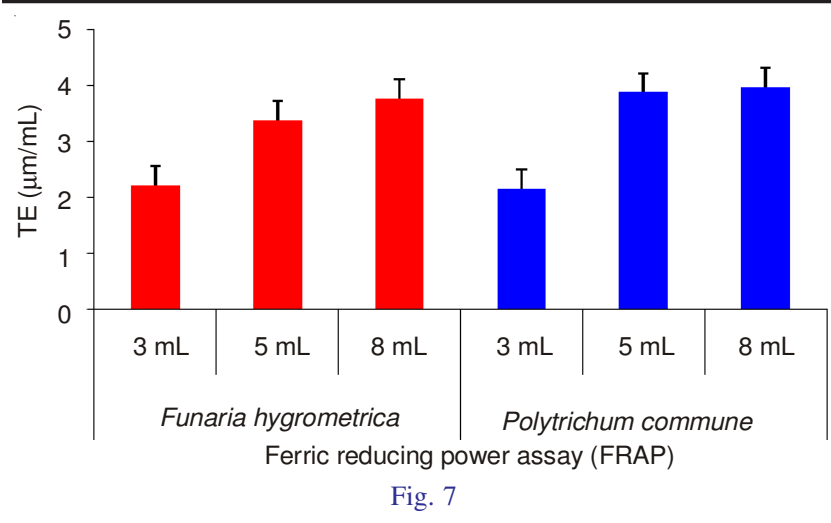

$\%$ age scavenging of superoxide radical anion. The decrease in absorbance at $560 \mathrm{~nm}$ with the sample and the standard compound quercetin indicates their abilities to quench superoxide radicals in the reaction mixture. The results of this assay showed that $\%$ age scavenging of superoxide radical anion is higher for Polytrichum commune (56.3). The methanol extract of Funaria hygrometrica showed a slightly less \% age scavenging of superoxide radical anion (17.32) (Fig. 8).

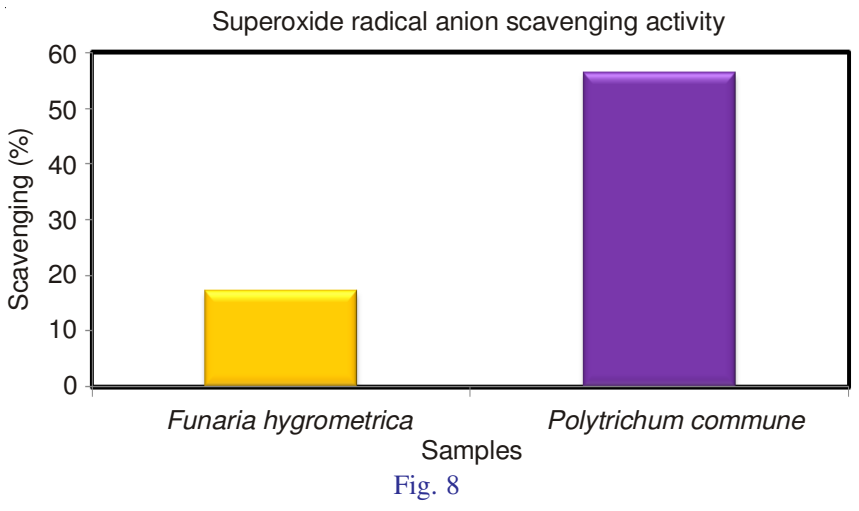

Metal chelating activity: Iron is known to generate free radicals through the Fenton and Haber-Weiss reaction. Metal ion chelating activity of an antioxidant molecule prevents oxyradical generation and the consequent oxidative damage. Metal ion chelating capacity plays a significant role in antioxidant mechanism since it reduces the concentration of the catalyzing transition metal. The methanol extract showed the maximum value of percentage of bound iron with Funaria hygrometrica (49.29), while the other plant sample (Polytrichum commune) also show metal chelating activity but the value of percentage of bound iron is lesser (41.9) (Fig. 9).

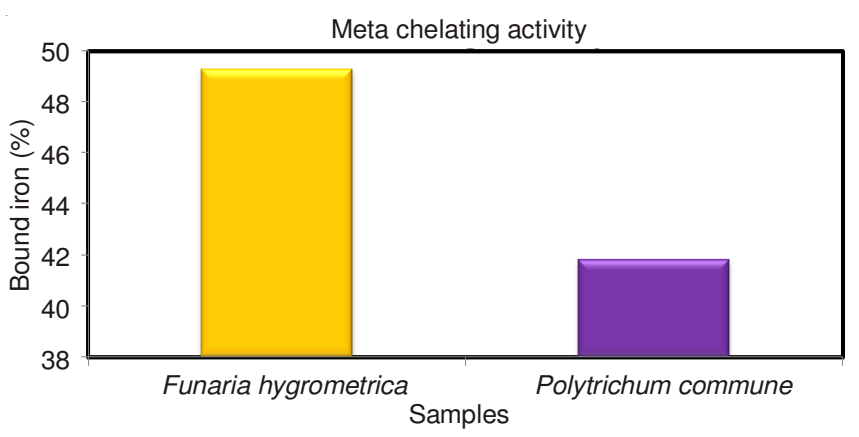

Fig. 9
FRAP Essay: The FRAP (Ferric reducing antioxidant power) assay employed ferrictripyridyltriazine complex $\mathrm{Fe}$ (III)-(TPTZ) $2 \mathrm{Cl} 3$ (pale yellow in colour) as an oxidizing agent, When it came in contact with an antioxidant, it gets reduced to $\mathrm{Fe}$ (II)-(TPTZ) ${ }_{2} \mathrm{Cl}_{3}$ (Blue in colour) and absorbs at $593 \mathrm{~nm}$. The results of FRAP assay are often expressed in FRAP units. A FRAP unit can be defined as the reduction of ferric(III) to ferrous(II). A higher FRAP value referred to a higher reducing ability of the sample which means a higher antioxidant potential. The methanolic extract of Polytrichum commune showed the highest FRAP value (3.96 TE $\mu \mathrm{M} / \mathrm{mL})$, referring to highest antioxidant potential. While the other methanol extract have a comparatively less antioxidant potential (3.761 TE $\mu \mathrm{M} / \mathrm{mL})$ (Fig. 10).

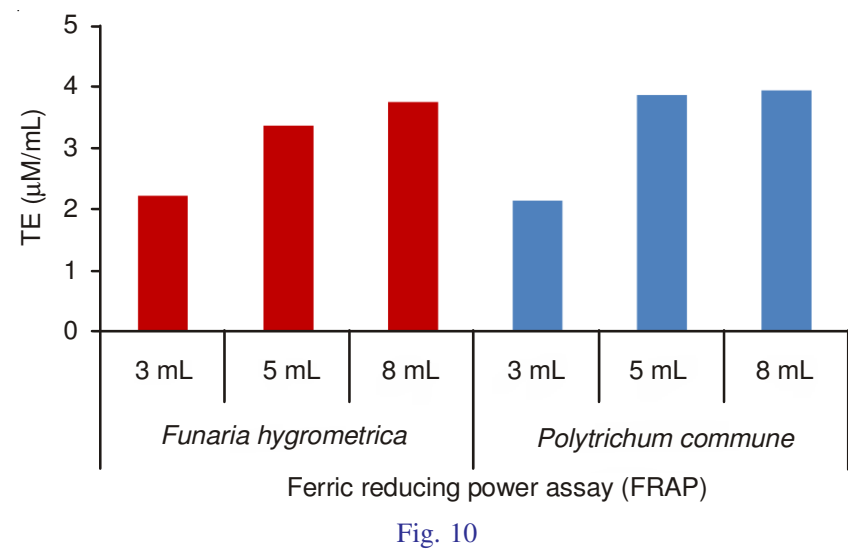

\section{Conclusion}

In the past few years interest in the search of new natural antioxidants has grown because reactive oxygen species (ROS) production and oxidative stress is linked to many diseases. The use of synthetic antioxidants generally leads to problems of toxicity. In this study, antioxidant potential of methanol extracts of two different plants from the bryophytes were assayed by FTC, DPPH, ABTS, TFC, TPC, TCA, FRAP and metal chelating effect methods. The antioxidant activity of the extracts was also studied using linear regression analysis and found strongly correlated with total phenolic contents.

\section{REFERENCES}

1. F. Pourmorad, S.J. Hosseinimehr and N. Shahabimajd, Afr. J. Biotechnol., 5, 1142 (2006).

2. S.N. Raja, H. Ahamad and V. Kumar, Antioxidant Activity in Some Selected Indian Medicinal Plants. Cytisusscoparius Link-A Natural Antioxidant, 6, 1 (2006).

3. V. Prakash, P.K. Mishra and M. Mishra, J. Med. Plants Res, 3, 608 (2009).

4. P.D. Duh, Y.Y. Tu and G.C. Yen, LWT-Food Sci. Technol., 32, 269 (1999).

5. S. Dragland, H. Senoo, K. Wake, K. Holte and R. Blomhoff, J. Nutr., 133, 1286 (2003).

6. S.Y. Wang, Acta Hortic., 620, 461 (2003).

7. X. Wu, G.R. Beecher, J.M. Holden, D.B. Haytowitz, S.E. Gebhardt and R.L. Prior, J. Agric. Food Chem., 52, 4026 (2004).

8. J.M. Glime, Economic and Ethnic uses of Bryophytes, In: Flora of North America: North of Mexico, Flora of North America Editorial Committee, Oxford University Press, New York, Vol. 27, Part 1, pp,1441 (2007).

9. E.S.J. Harris, Bryologist, 111, 169 (2008).

10. P. Valentao, E. Fernandes, F. Carvalho, P.B. Andrade, R.M. Seabra and M.L. Bastos, Biol. Pharm. Bull., 25, 1320 (2002). 
11. H.P.S. Makkar, M. Blummel, N.K. Borowy and K. Becker, J. Sci. Food Agric., 61, 161 (1993).

12. T. Osawa and M. Namiki, Agric. Biol. Chem., 45, 735 (1981).

13. P. Erasto, G. Bojase-Moleta and R.R.T. Majinda, Phytochemistry, 65 , 875 (2004).

14. R. Re, N. Pellegrini, A. Proteggente, A. Pannala, M. Yang and C. RiceEvans, Free Radic. Biol. Med., 26, 1231 (1999).

15. F.F. Benzie and J.J. Strain, Methods Enzymol., 299, 15 (1999).

16. V. Dewanto, X. Wu, K.K. Adom and R.H. Liu, J. Agric. Food Chem., 50, 3010 (2002).

17. T.C.P. Dinis, V.M.C. Madeira and L.M. Almeida, Arch. Biochem. Biophys., 315, 161 (1994).

18. M. Nishikimi, N. Appaji Rao and K. Yagi, Biochem. Biophys. Res. Commun., 46, 849 (1972).
19. M.P. Kahkonen, A.L. Hopia, H.J. Vuorela, J.P. Rauha, K. Pihlaja, T.S. Kujala and M. Heinonen, J. Agric. Food Chem., 47, 3954 (1999).

20. T. Fargere, M. Abdennadher, M. Delmas and B. Boutevin, Eur. Polym. J., 31, 489 (1995).

21. B. Delazar, B. Talischi, Z. Nazemiyeh, H. Rezazadeh, L. Nahar and S.D. Sarker, Braz. J. Pharmacogn., 16, 286 (2006).

22. S.M. Upasani, H.M. Kotkar, P.S. Mendki and V.L. Maheshwari, Pest Manag. Sci., 59, 1349 (2003).

23. V. Gorduza, C. Tarabasanu-Mihaila, V. Gorduza, C. Cernatescu and M. Rusu, Ovidius Univ. Annals Chem., 11, 56 (2000).

24. D. Amic, D. Davidovic-Amic, D. Beslo and N. Trinajstic, Croat. Chem. Acta, 76, 55 (2003). 